\title{
Serum tumor marker detection on PEGylated lipid membrane using biosensor based on total internal reflection imaging ellipsometry
}

\author{
Yibang Zhang a,b,c, Yanyan Chen ${ }^{\mathrm{a}, *}$, Gang Jin ${ }^{\mathrm{a}, \mathrm{b}, \mathrm{d}, * *}$ \\ a Suzhou Institute of Nano-Tech and Nano-Bionics, Chinese Academy of Sciences, Suzhou, Jiangsu 215125, PR China \\ b Institute of Biophysics, Chinese Academy of Sciences, Beijing 100101, PR China \\ ' Graduate University of Chinese Academy of Sciences, Beijing 100049, PR China \\ d Institute of Mechanics, Chinese Academy of Sciences, Beijing 100190, PR China
}

\section{A R T I C L E I N F O}

\section{Article history:}

Received 10 November 2010

Received in revised form 26 May 2011

Accepted 13 June 2011

Available online 23 June 2011

\section{Keywords:}

PEGylated phospholipid membrane

Total internal reflection imaging

ellipsometry

CA19-9

\begin{abstract}
A B S T R A C T
We describe highly sensitive, label-free, real time detection of the biomarker CA19-9 using microarray biosensors based on total internal reflection imaging ellipsometry (TIRIE), in which anti-CA19-9 is immobilized onto the PEGylated phospholipid membrane. Strong resistance against non-specific adsorption of PEGylated lipid membrane allows direct serum assay without the blocking agent. We find that PEG density has an influence on antibody assembly and only a proper amount of PEG is appropriate for antigen binding. Two different methods for antibody assembly are compared and finally protein $\mathrm{A}$ is preferred due to its higher protein binding efficiency. The estimated detection limit of CA19-9 is $18.2 \mathrm{U} / \mathrm{ml}$, which is lower than the cut-off value for normal level $(37 \mathrm{U} / \mathrm{ml})$. Regression analysis between the results of microarray biosensor and electrochemiluminescence immunoassay (ECLIA) suggests a high correlation $(R=0.989)$. The capability for real-time monitoring of tumor marker with high sensitivity and selectivity in clinically relevant samples opens up substantial possibilities for early cancer diagnosis and treatment.
\end{abstract}

(c) 2011 Elsevier B.V. All rights reserved.

\section{Introduction}

As popular awareness of the importance of cancer early detection increases, the devices and methods which can perform quick and accurate tumor markers detection are becoming more and more compelling. Microarray biosensor with multiple advantages, such as low sample consumption, fast response time and high throughput, [1-4] appears to be a promising alternative. A novel microarray biosensor based on total internal reflection imaging ellipsometry (TIRIE) was recently developed for kinetic measurement of biomolecular interaction, which is integrated by imaging ellipsometer and microfluidic reactor system $[5,6]$. Compared with traditional imaging ellipsometry, TIRIE has higher phase sensitivity since it applies an evanescent wave as optical probe to detect the biomolecular adsorption and interaction process [7]. The use of evanescent field makes real time measurements not be disturbed by refractive index non-uniformity of solution. Besides, with the

\footnotetext{
* Corresponding author at: Suzhou Institute of Nano-Tech and Nano-Bionics, Chinese Academy of Sciences, Suzhou, Jiangsu 215125, PR China. Tel.: +86512 62872596; fax: +8651262872562.

** Corresponding author at: Institute of Mechanics, Chinese Academy of Sciences, Beijing 100190, PR China. Tel.: +86 10 82544138; fax: +8610 82544137.

E-mail addresses: yychen2006@sinano.ac.cn (Y. Chen), gajin@imech.ac.cn (G. Jin).
}

help of microfluidic system, multiple biomolecular interactions can be measured at the same time.

Unfortunately, non-specific adsorption of biomolecules is a persistent challenge in microfluidic biosensors [8]. A variety of non-fouling materials have been synthesized during the past decades and some of them have been successfully applied worldwide, such as poly(ethylene glycol) (PEG) and poly(ethylene oxide) (PEO) [9-12]. Supported phospholipid membrane has also shown good validity in preventing protein adsorption [13-15]. With its self-assembly property, flexibility and two-dimensional fluidity, phospholipid membranes have promising applications in the study of membrane proteins or ion channels [16]. However, few model lipid bilayers, to our knowledge, are used for assembling nonmembrane proteins [17].

CA19-9 is a carbohydrate tumor-associated antigen which is originally isolated from a hybridoma [18]. Although guidelines from the American Society of Clinical Oncology discourage the use of CA19-9 as a test for cancer, especially for pancreatic cancer (because increased levels of CA19-9 are also found in non-malignant conditions [19-23]), it can still be used to see whether a pancreatic tumor is secreting it; if that is the case, then the levels should fall when the tumor is treated, and they may rise again if the disease recurs [24-26]. Presently, the clinical measurement of CA19-9 mainly depends on electrochemiluminescent immunoassay (ECLIA) $[27,28]$. Although possessing high sensitivity and a 
(a)

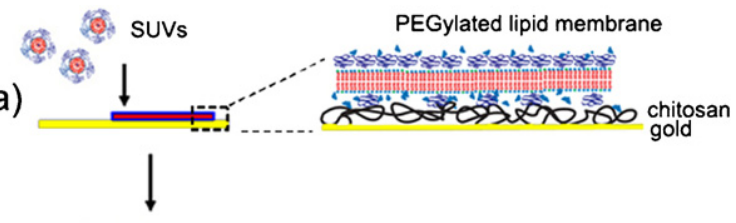

(b)

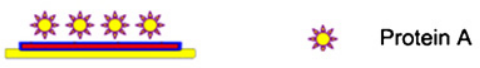

(c)

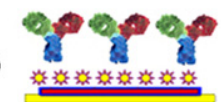

(d)

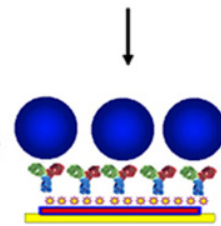

(e)

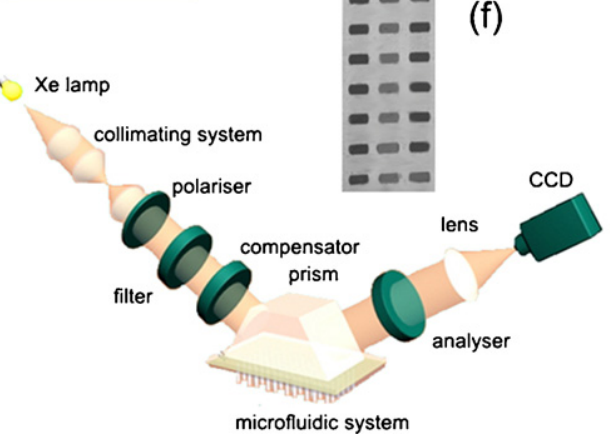

Fig. 1. Flow chart of CA19-9 detection on PEGylated phospholipid membrane and schematic view of total internal reflection ellipsometry imaging biosensor. (a) Phospholipid membrane formation through SUVs; (b) protein A coupling on phospholipid membrane; (c) antibody attachment; (d)CA19-9 binding; (e)principal view of biosensor; (f) a typical microarray image by TIRIE.

broader detection range, the method still has a few technical problems including multiple reaction steps, time-consuming and certain possibility of false results due to nonspecific adsorption. In this article, monoclonal antibodies of CA19-9 were immobilized onto lipid membrane surface for CA19-9 detection. The flow chart is shown in Fig. 1. The system performance of the microarray biosensor based on TIRIE was tested for the determination of CA19-9 level in human serum samples and the results were compared with the conventional ECLIA.

\section{Experimental}

\subsection{Materials}

1,2-Dimyristoyl-sn-glycero-3-phophatidylcholine

(DMPC), 1,2-distearoyl-sn-glycero-3-phosphoethanolamine- $N$ [carboxy(polyethylene glycol)2000] (DSPE-PEG $2000-\mathrm{COOH})$ and Mini-Extruder were purchased from AvantiPolar Lipid, Inc. (Alabaster, AL). All lipids were stored at $-20^{\circ} \mathrm{C}$ until use. CA19-9 and anti-CA19-9 were obtained from Shanghai LincBio Science Co. Ltd. Protein A (from Staphylococcus aureus), rabbit IgG, human serum albumin and fibrinogen were from Sigma. $N$-Hydroxysuccinimide (NHS) and $N$-ethyl- $N^{\prime}$-(3-diethylaminopropyl) carbodiimide (EDC) were from Acros. LMW chitosan (Mr: 10,000, 85\% deactylation) was from Jinan Haidebei Marine Bioengineering Co. Milli-Q ultrapure water with a resistivity $\sim 18 \mathrm{M} \Omega \mathrm{cm}$ (Millipore, Molsheim, France) was used for all the solutions. Other chemicals used were of analytical grade or better.

\subsection{Substrate preparation}

The SF10 glass slide was used as substrate and was prepared by the evaporation of $2 \mathrm{~nm}$ of chromium followed by $30 \mathrm{~nm}$ of gold. Gold coated glass slides were all pre-cleaned with piranha solution $\left(98 \% \mathrm{H}_{2} \mathrm{SO}_{4}: 30 \% \mathrm{H}_{2} \mathrm{O}_{2}=3: 1, \mathrm{v} / \mathrm{v}\right)$. After the immersion of the gold coated glass slides into the chitosan solution $(10 \mathrm{mg} / \mathrm{ml})$ for at least $1 \mathrm{~h}$, chitosan will spontaneously absorb onto the surface. The slides were stored at $4{ }^{\circ} \mathrm{C}$ after ultrapure water rinsing and nitrogen gas drying.

\subsection{Phospholipid membrane formation}

The microfluidic reactor developed in our laboratory was used to fabricate microarray on the solid surface. Phospholipid membrane was formed by small unilamellar vesicles (SUVs) adsorption and rupture on the chitosan coated gold surface. Preparation of SUVs was carried out via the extrusion method [29]. Vesicles solution was stored at $4{ }^{\circ} \mathrm{C}$ until use. $10 \mu \mathrm{l}$ of vesicles was introduced into each chamber at $1 \mu \mathrm{l} / \mathrm{min}$ followed by rinsing with water $(10 \mu \mathrm{l} / \mathrm{min}$, $10 \mathrm{~min}$, same for below rinsing procedure) to remove excess vesicles.

\subsection{Proteins binding on phospholipid membrane}

In order to couple proteins by their amino groups, NHS/EDC was used to activate carboxylic group of PEG on the membrane surface. $25 \mu \mathrm{l}$ of NHS and EDC ( $50 \mathrm{mM} / 200 \mathrm{mM})$ mixture was pumped across the membrane surface at $3 \mu \mathrm{l} / \mathrm{min}$, followed immediately by an injection of $20 \mu \mathrm{l}$ anti-CA19-9 $(0.1 \mathrm{mg} / \mathrm{ml}, \mathrm{pH} 7.4$ with low salt strength) at $1 \mu \mathrm{l} / \mathrm{min}$. Phosphate buffered saline (PBS) ( $\mathrm{pH} 7.4$ ) was used to remove those non-specific adsorbed proteins and ultrapure water was used to wash off ions. Residual NHS esters were inactivated by further injection of $20 \mu$ l ethanolamine chloride [30] ( $1 \mathrm{M}$, $\mathrm{pH} 8.5)$ at $5 \mu \mathrm{l} / \mathrm{min}$. $20 \mu \mathrm{l} \mathrm{CA19-9}$ was added with a flow rate of $1 \mu \mathrm{l} / \mathrm{min}$ followed by PBS and ultrapure water washing.

Protein A, which has specific interaction with the Fc constant region of IgG molecules, was also used to antibody site-oriented coupling. After NHS/EDC activation, $20 \mu \mathrm{l}$ protein A $(0.1 \mathrm{mg} / \mathrm{ml}, \mathrm{pH}$ 4.5) was injected. After using ethanolamine chloride to deactivate residual NHS esters, $20 \mu \mathrm{l}$ anti-CA19-9 $(0.1 \mathrm{mg} / \mathrm{ml}, \mathrm{pH} 7.4)$ was pumped at $1 \mu \mathrm{l} / \mathrm{min}$. PBS was used to remove those non-specific adsorbed proteins. Finally $20 \mu \mathrm{l}$ CA19-9 or serum was pumped at $1 \mu \mathrm{l} / \mathrm{min}$ followed by PBS and ultrapure water washing.

\subsection{CA19-9 detection}

Pure CA19-9 antigen was diluted with PBS into a series of ladder solutions to establish a dose-response curve. Data analysis and curve fitting were performed with four-parameter logistic function fitting.

Serum collected from 25 patients who were diagnosed with gastric cancer, colorectal cancer and liver cancer (The sample collection took place in Shandong Cancer Hospital. Written informed consent was obtained from each subject) were stored at $-70^{\circ} \mathrm{C}$. Frozen serum samples were thawed on ice and spun at $2000 \mathrm{rpm}$ for $5 \mathrm{~min}$ at $4{ }^{\circ} \mathrm{C}$ before the assay. The ECLIA measurement of CA199 in patient serum was carried out using CA19-9 immunoassay Kits (Roche Elecsys 2010). All of ECLIA operations were performed in the Institute of Materia Medica, Shandong Academy of Medical Science.

\subsection{Sensitivity, selectivity and reproducibility}

Sensitivity or the minimum detection limit was determined by adding three standard deviations to the mean grayscale values of 10 zero standard duplicates. Selectivity was assessed by cross-reaction 
with the mixture of IgG, HSA and fibrinogen $(0.1 \mathrm{mg} / \mathrm{ml}$ for each protein). Intra-slide variation was calculated as the mean coefficient of variation (CV) of six duplicate spots for CA19-9 detection $(37 \mathrm{U} / \mathrm{ml}$ ), averaged from three slides. For the assessment of interslide variation the $\mathrm{CV}$ between mean signals on three replicate slides was calculated.

\subsection{Total internal reflection imaging ellipsometry (TIRIE)}

The principle of TIRIE can be found elsewhere [31,32] and a schematic diagram of the TIRIE biosensor setup is shown in Fig. 1e. The TIRIE biosensor is a coupling of the optical system and a microfluidic protein reactor array system by a prism $[5,6]$. The optical system is an imaging ellipsometer with a light source of Xe lamp and a wavelength $633 \mathrm{~nm}$. The incident light beam goes through the polarizer, the compensator and the $59^{\circ}$ prism where the evanescent wave is used as optical probe to detect the protein adsorption and interaction process. Gold coated glass slide as substrate tightly contact the prism with an index matching liquid (refractive index $n=1.73$ ). The incident light beam is reflected at the interface between the substrate and the tested solution and then passes through the analyzer and is focused on a sensing area of the charge coupled device (CCD) camera. The image signal corresponding to the biomolecular mass surface concentration distribution is recorded in 16-bit $(0-65,536)$ grayscale format in a computer for further analysis. A microfluidic reactor array generated by soft lithography is attached to the substrate surface to form a 24 independent cell array. Each cell has its own inlet and outlet for solution delivery by a peristaltic pump. Sample consumption of each cell can be as little as $150 \mathrm{nl}$. Fig. $1 \mathrm{f}$ shows the schematic view of TIRIE and a real imaging photo. After analyzing the photos captured in timelapse mode during bimolecular interaction, the kinetic changes of
Table 1

Comparison of grayscales changes and signal recovery rates of PEGylated lipid membranes before and after reaction with serum.

\begin{tabular}{lccc}
\hline PEG, mol\% & \multicolumn{2}{l}{ Grayscales } & \multirow{2}{*}{ Recovery rate } \\
\cline { 2 - 3 } & Before serum reaction & After serum reaction & \\
\hline 0.5 & $13,435.69 \pm 15.83$ & $13,523.92 \pm 12.64$ & $100.67 \%$ \\
3 & $13,892.47 \pm 14.99$ & $13,918.55 \pm 11.40$ & $100.19 \%$ \\
10 & $14,691.46 \pm 16.58$ & $14,714.23 \pm 14.00$ & $100.15 \%$ \\
\hline
\end{tabular}

grayscale values against the time can be presented as a curve. The information of biomolecular interaction is obtained by analyzing the real-time process.

\section{Result and discussion}

\subsection{Serum resistance of phospholipid membrane}

Nonspecific adsorption is expected to limit the sensitivity of biosensors when used for the estimation of specific analytes in serum. As a result, blocking agents [33,34] (e.g., bovine serum albumin, casein and detergents) are necessary to help reduce non-specific protein adsorption. Here, we would like to introduce PEGylated phospholipid membrane self-assembled on the biosensor surface in serum biomarker detection without using blocking agent. Serum resistance of phospholipid membrane was thereupon firstly examined by TIRIE. From the dynamic TIRIE curves of phospholipid membrane reacting with serum, signal increase caused by serum adsorption can be reduced back to the original stage after PBS rinsing, which is shown in Fig. $2 \mathrm{~A}$ and Table 1. It is worth noting that the signal recovery increases with increasing content of PEG. High density PEG brush floating on the membrane surface can prevent
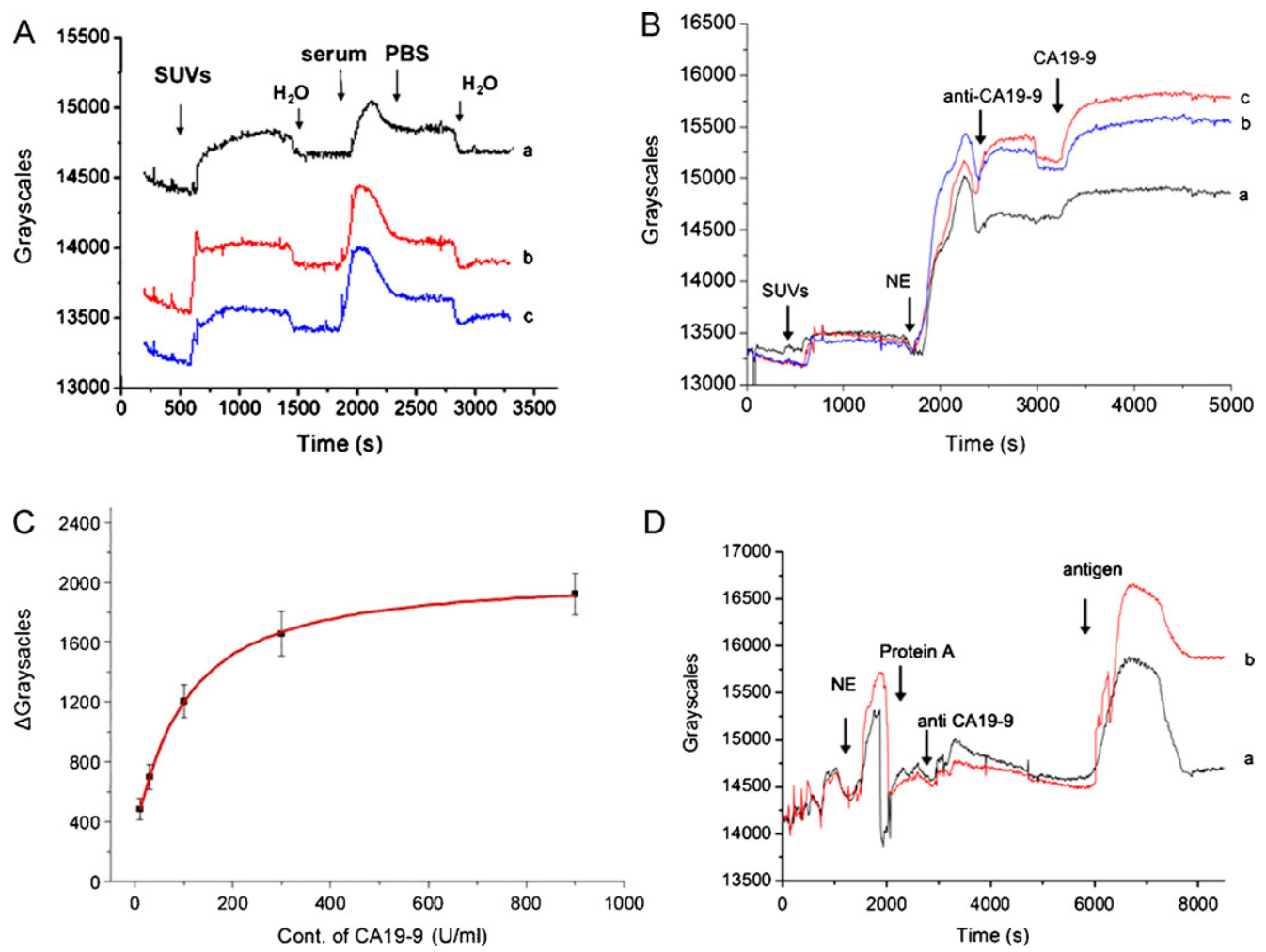

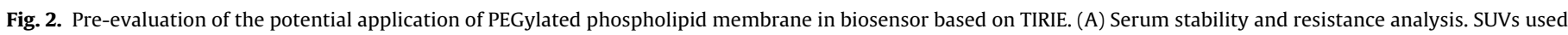

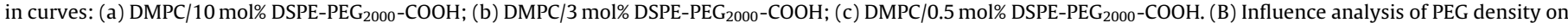

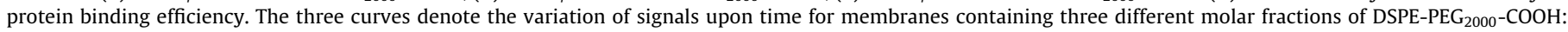

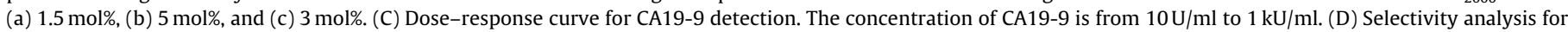
CA19-9 detection. Antigen used in curve (a) is the mixture of IgG, HSA and fibrinogen, while CA19-9 as antigen for (b). 

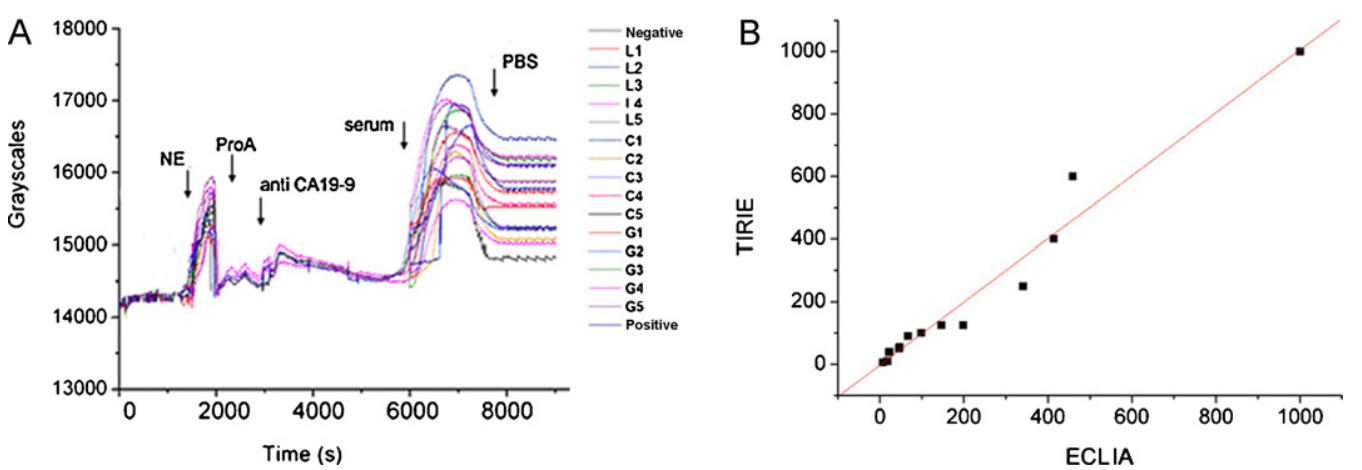

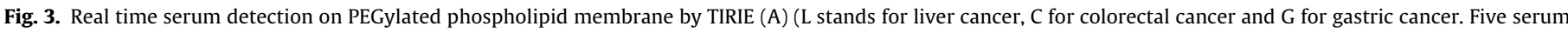
samples are selected at random for each type of cancer) and correlation analysis between results measured by biosensor based on TIRIE and ECLIA (B).

adsorption of serum macromolecules, and smaller molecules can come close to those membranes lacking enough PEG shielding and be trapped within spaces among PEG mushroom [35,36], but their signal recovery ratios after serum exposing and buffer washing are almost $100 \%$.

\subsection{Antibody binding on phospholipid membrane}

We have examined protein assembly efficiency of membranes containing three different molar contents of PEG, which were $1.5 \mathrm{~mol} \%, 3 \mathrm{~mol} \%$ and $5 \mathrm{~mol} \%$. Interestingly, grayscales addition of membranes after protein binding is not improved while the molar fraction of PEG increases (Fig. 2B). It is not difficult to understand that too low level of PEG is neither enough for nonspecific adsorption resistance, nor for protein assembly. In contrast, too much PEG maintains a strong ability against nonspecific adsorption, but it may hinder the attachment of proteins, due to the increased hydration repulsion.

Furthermore, as an improvement, protein $\mathrm{A}$ is also used for antibody immobilization on the membrane, which ensures that the binding site of the immobilized antibody remains accessible for antigen binding [37]. Table 2 is the comparison of two antibody immobilization methods. Despite the signal addition of antibody immobilized on protein $\mathrm{A}$ is lower, the final grayscales addition after reaction with the same antigen is doubled compared with direct antibody binding, which suggests that oriented and bioaffinity immobilization strategy works better in our system.

Patel et al. [38] who assessed the effect of the accessibility of terminal carboxylated groups of SAMs on the reaction with NHS and the immobilization of the protein catalase, reported the ordered arrangement of the homogeneous SAM would sterically hinder the interaction with proteins, while with increased disorder the terminal carboxylated groups are more accessible for immobilization. The PEG chains employed here were linked to a two dimensionally fluid phospholipid bilayers, rather than grafted at fixed locations on the surface. Thus, the polymer chains are more flexible and able to reorganize to accommodate incoming protein molecules.

\subsection{Dose-response analysis}

A dose-response curve shown in Fig. 2C, where the grayscale value is plotted against the concentration of CA19-

Table 2

Comparison of grayscales changes under two different protein immobilization strategies.

\begin{tabular}{llc}
\hline Immobilization strategies & \multicolumn{2}{|l}{$\Delta$ Grayscales } \\
\cline { 2 - 3 } & Anti-CA19-9 coupling & CA19-9 binding \\
\hline NHS/EDC & $219.18 \pm 12.62$ & $503.13 \pm 17.49$ \\
Protein A & $60.15 \pm 22.18$ & $1092.01 \pm 8.27$ \\
\hline
\end{tabular}

9, can also be represented by the regression equation: $y=2036.49-1657.96 /(1+x / 101.99)^{1.16} \quad\left(R^{2}=0.999\right.$, where $y$ is grayscale value and $x$ is the concentration of CA19-9).

\subsection{Sensitivity, selectivity and reproducibility}

The sensitivity was determined using five-fold serial diluted samples representing CA19-9 as a reference for zero standard measurement. The mean value of grayscale change determined by ten zero standard replicates was 10.4 , and the minimum detection limit of CA19-9 was as low as $18.2 \mathrm{U} / \mathrm{ml}(\mathrm{S} / \mathrm{N}=3)$, which is lower than the cut-off value for normal level $(<37 \mathrm{U} / \mathrm{ml})$ [39]. We believe the detection limit can still be lowered through further machine updating and parameters optimization.

The effect of substances that might interfere with the response of the biosensor was also studied. A mixture of human IgG, albumin and fibrinogen was used to test the selectivity of the biosensor system for CA19-9. The grayscale change of the mixture after PBS washing was much lower than the detection limit of CA199. (Fig. 2D) These results suggested that the system was specific to CA19-9.

Inter-slide precision was determined by calculating the CV of three duplicate reactions with the same sample (37 U/ml CA19-9), while a measure for intra-slide precision was the CV of six spots within one slide, averaged from three slides. CV values calculated for intra-slide and inter-slide were $9.7 \%$ and $18.8 \%$ separately, indicating the method has good reproducibility.

\subsection{Determination of CA19-9 in serum and comparison with ECLIA}

The analysis of CA19-9 using microarray biosensor based on TIRIE and ECLIA techniques were done on the same serum samples. Totally 15 serum samples were analyzed (Fig. 3A) and the concentrations were found in the range of $6.64-1020.51 \mathrm{U} / \mathrm{ml}$. Comparisons between the two analysis techniques were done by the regression line method (shown in Fig. 3B). The regression equation of the concentration of CA19-9 obtained from the TIRIE $(y)$ and ECLIA $(x)$ is $y=1.008 x-2.123$, with a correlation coefficient of 0.989 . Thus, there is no evidence for systematic differences between the two methods.

\section{Conclusion}

In order to avoid nonspecific adsorption during serum biomarker analysis, PEGylated phospholipid membrane is developed and applied as surface modification for biosensors based on TIRIE. Taking advantage of such an inert surface, our microarray biosensor demonstrates a promising serum tumor marker measurement without pre-treatment or dilution. Compared with 
conventional ECLIA, our assay is performed in real time and direct detection for serum biomarkers is also realized with high sensitivity and acceptable selectivity. In conclusion, with PEGylated phospholipid membrane, microarray biosensor based on TIRIE provides apparent advantages and exhibits potential in early cancer screening and immunological assays.

\section{Acknowledgements}

The authors would like to gratefully acknowledge financial supports from Ministry of Science and Technology of China (2008AA02Z419, 2009CB320302), Natural Science Foundation (10804083, 20845003) of China, Chinese Academy of Sciences (KJCX2-YW-M04, KJCX2-YW-M03) and Key Laboratory of Microgravity, Institute of Mechanics, CAS.

\section{References}

[1] G. MacBeath, S.L. Schreiber, Science 289 (2000) 1760-1763.

[2] B.B. Haab, M.J. Dunham, P.O. Brown, Genome Biol. 2 (2001) 1-13.

[3] M. Schena, Protein Microarray, Jones and Bartlett Publisher, MA, 2005

[4] E. Özkumur, J.W. Needham, D.A. Bergstein, R. Gonzalez, M. Cabodi, J.M. Gershoni, B.B. Goldberg, M.S. Ünlu, Proc. Natl. Acad. Sci. U.S.A. 105 (2008) 7988-7992

[5] Y.Y. Chen, Z.H. Wang, Y.H. Meng, G. Jin, Int. J. Nanotechnol. 4 (2007) 171-178

[6] L. Liu, Y.Y. Chen, Y.H. Meng, S. Chen, G. Jin, Thin Solid Films 519 (2011) 2758-2762.

[7] M. Poksinski, H. Arwin, Opt. Lett. 32 (2007) 1308-1310.

[8] S. Choi, J. Chae, J. Micromech. Microeng. 20 (2010) 075015.

[9] M.M. Li Deng, M. George, Whitesides, J. Am. Chem. Soc. 118 (1996) 51365137.

[10] R. Chapman, E. Ostuni, S. Takayama, R.E. Holmlin, L. Yan, G.M. Whitesides, J. Am. Chem. Soc. 122 (2000) 8303-8304.

[11] R.E. Holmlin, X. Chen, R.G. Chapman, S. Takayama, G.M. Whitesides, Langmuir 17 (2001) 2841-2850.

[12] E. Ostuni, R.G. Chapman, R.E. Holmlin, S. Takayama, G.M. Whitesides, Langmuir 17 (2001) 5605-5620.

[13] E. Sackman, Science 271 (1996) 43-48.

[14] A.L. Plant, Langmuir 15 (1999) 5128-5135.

[15] X. Song, B.I. Swanson, Anal. Chem. 71 (1999) 2097-2107.

[16] E.T. Castellana, P.S. Cremer, Surf. Sci. Rep. 61 (2006) 429-444.

[17] J.R. Joubert, K.A. Smith, E. Johnson, J.P. Keogh, V.H. Wysocki, B.K. Gale, J.C. Conboy, S.S. Saavedra, ACS Appl. Mater. Int. 1 (2009) 1310-1315.

[18] H. Koprowski, Z. Steplewski, K. Mitchell, M. Herlyn, D. Herlyn, P. Fuhrer, Somat. Cell Mol. Genet. 5 (1979) 957-971.
[19] Y.J. Kawamura, A. Tokumitsu, J. Sasaki, S. Tsujinaka, T. Maeda, K. Mizogami, F. Konishi, Gastroenterol. Res. Pract. 2009 (2009) 780263-780266.

[20] Y. Matsuoka, K. Endo, Y. Kawamura, T. Yoshida, T. Saga, Y. Watanabe, M. Koizumi, T. Nakashima, J. Konishi, N. Yamaguchi, R. Yatani, Cancer 65 (1990) 506-510.

[21] P.J. Monaghan, M.B. Leonard, W.D. Neithercut, M.G.T. Raraty, R. Sodi, Clin. Chim. Acta 406 (2009) 41-44

[22] K. Inoue, K. Okada, Y. Taki, R. Goto, S. Kinomura, T. Kaneta, H. Fukuda, HepatoGastroenterology 55 (2008) 46-49.

[23] K. Inoue, K. Okada, Y. Taki, R. Goto, S. Kinomura, T. Kaneta, H. Fukuda, Eur. J. Nucl. Med. Mol. Imaging 33 (2006) S83.

[24] M.J. Chung, S.P. Hong, S.M. Bang, S.W. Park, J.S. Seoung, W.J. Lee, J.B. Chung, S.Y. Song, J. Gastroenterol. Hepatol. 24 (2009) A129-A1129.

[25] U. Halm, J. Clin. Oncol. 24 (2006) 5610.

[26] C.R. Ferrone, D.M. Finkelstein, S.P. Thayer, A. Muzikansky, C. Fernandez-del Castillo, A.L. Warshaw, J. Clin. Oncol. 24 (2006) 2897-2902.

[27] X.G. Ni, X.F. Bai, Y.L. Mao, Y.F. Shao, J.X. Wu, Y. Shan, C.F. Wang, J. Wang, Y.T. Tian, Q. Liu, D.K. Xu, P. Zhao, Eur. J. Surg. Oncol. 31 (2005) 164-169.

[28] J.H. Lin, F. Yan, X.Y. Hu, H.X. Ju, J. Immunol. Methods 291 (2004) 165-174.

[29] Y.B. Zhang, Y.Y. Chen, G. Jin, Langmuir 26 (2010) 11140-11144.

[30] M.A. Cooper, Nat. Rev. Drug Discov. 1 (2002) 515-528.

[31] M. Poksinski, H. Dzuho, H. Arwin, Corros. Corros. Prot. 2001 (2001) 1002-1008.

[32] H. Arwin, M. Poksinski, K. Johansen, Appl. Opt. 43 (2004) 3028-3036.

[33] J.G. Kenna, G.N. Major, R.S. Williams, J. Immunol. Methods 85 (1985) 409-419.

[34] E. Wedege, G. Svenneby, J. Immunol. Methods 88 (1986) 233-237.

[35] D. Marsha, R. Bartucci, L. Sportelli, Biochim. Biophys. Acta 1615 (2003) 33-59.

[36] D. Marsh, Biophys. J. 81 (2001) 2154-2162.

[37] F. Rusmini, Z. Zhong, J. Feijen, Biomacromolecules 8 (2007) 1775-1789.

[38] N. Patel, M.C. Davies, M. Hartshorne, R.J. Heaton, C.J. Roberts, S.J.B. Tendler, P.M. Williams, Langmuir 13 (1997) 6485-6490.

[39] B.C.D. Villano, S. Brennan, P. Brock, C. Bucher, V. Liu, M. McClure, B. Rake, S. Space, B. Westrick, H. Schoemaker, Clin. Chem. 29 (1983) 549-552.

\section{Biographies}

Yibang Zhang received Ph.D. Degree in Institute of Biophysics, Chinese Academy of Science, Beijing, China. He joined Suzhou Biopharmagen Co. as a post-doc researcher in 2011. His interests are label-free protein biosensors and tumor targeting therapy.

Yanyan Chen received Ph.D. degree in Institute of Mechanics, Chinese Academy of Science, Beijing, China. She joined Suzhou Institute of Nano-tech and Nano-bionics, Chinese Academy of Science in 2006 as Associate Professor. Her research interests are biosensors based on imaging ellipsometry and its biomedical application.

Gang Jin received Ph.D. degree in Physics from Pierre et Marie Curie Univ de Paris, \&ESPCI, France. He is currently working as Full Professor in Institute of Mechanics, Chinese Academy of Science, Beijing, China. His research interests are ellipsometers including label-free biosensors based on imaging ellipsometry, instrumentation and application. 